\title{
Cultural Competency: A Framework for Equity, Diversity, and Inclusion in the Archival Profession in the United States
}

\author{
Ellen Engseth
}

\begin{abstract}
This article explores cultural competency in the context of the archival profession in the United States. The author reviews the cultural competency framework; and the pertinent literature of archives, library, and information studies (LIS) and beyond; and surveys activity within the archival field. The author also connects cultural competency to archival principles and practice, and offers a call for further research to develop cultural competency within the profession. Cultural competency is offered as a framework for equity, diversity, and inclusion work that is accessible and available to all, and as one that provides a way forward particularly for dominant-culture archivists. Furthermore, archivists can contribute uniquely to the discourse on cultural competency within LIS; this article responds to the call for, and encourages more, discourse with LIS.
\end{abstract}

(c) Ellen Engseth. (cc) BY-NC

\section{KEY WORDS}

Archival theory and principles, Collaboration, Cultural competency, Diversity, Intercultural competency, Inclusion, Library and information science 
$I^{\mathrm{ses}}$

begin with a personal note, in the spirit of cultural competency which is grounded in self-awareness. This article developed from my exploration of cultural competency as a member of the archival profession's dominant demographic and culture. Furthermore, my career is largely within higher education in predominantly white institutions; these can and often do support dominant systems to the exclusion of others. And, the two professions to which I belong, archival and library, in the United States are themselves majority-culture based and racially constructed. Cultural competency is part of my journey into systems, privilege, and culture, and their roles in professional practice and theory. In this article, I consider the connection between cultural competency and archives in the United States and set it within broad literature and practice for context. I posit that cultural competency is an avenue available to all of us and provides one way forward for dominant-culture archivists and librarians to advance equity, diversity, and inclusion. Additionally, archivists can respond to the call for discourse on cultural competency across library and information science and contribute uniquely to it. This article summarizes the archival profession's emergent involvement with cultural competency, affirms the value of cultural competency as a framework, and offers a call for more research and analysis.

\section{Cultural Competency Defined and Explored}

Cultural competency, variably known as intercultural competency, cross-cultural competency, cultural diversity competency, global competency, international mindedness, among others, ${ }^{1}$ is multifaceted, flexible, and best understood as a framework or set of concepts. Cultural competency begins with an awareness of self; this self-cultural analysis reveals biases and values, among other things. Cultural competency is firmly process oriented, meaning it emphasizes growth, continuing work, and action. And the framework includes a concept of a continuum on which to locate oneself. In general, scholars and practitioners across disciplines agree that cultural competency is management of human interactions across our differences, with results of more appropriate and effective outcomes at the individual, relational, group, and organizational levels. ${ }^{2}$ Many definitions are available to us. Dennis Meissner's 2016 presidential address to the Society of American Archivists (SAA) offered the Intercultural Communication Institute's definition: "the set of cognitive, affective, and behavioral skills and characteristics that support appropriate and effective interaction in a variety of cultural contexts," a definition closely resembling that in the SAGE Encyclopedia of Intercultural Competence. ${ }^{3}$ The World Health Organization defines it in the context of global competency, simply ". . . as a demonstrated ability to work constructively with people across differences." ${ }^{4}$ 
When parsing the concept of cultural competency by its component words, the literature generally agrees upon an understanding of "culture" as shared actions of groups of people, expressed daily, that are the results of historically or socially transmitted customs and traditions. ${ }^{5}$ On the use of the term "competency," here it refers to ability developed over time rather than any set of concrete skills. In this context, the word communicates "having the capacity to function effectively" and "integrated intelligence that is part of and woven into every other skill and competency." ${ }^{\circ}$ Thus, competency does not equate to cultural knowledge across all the world's cultures. It does not demand that one knows all. Rather, when competent, one is sensitive to self and to others, engages with others with humility, and knows that cultural differences exist as do similarities. ${ }^{7}$ Competency can be understood as capability.

Cultural competency emphasizes three aspects that together comprise effective interaction with difference. These are knowledge (cognitive), skills (behavioral), and attitudes (affective), or "KSAs," alternatively articulated as mindset, skillset, and heartset or the head, hand, heart components. Knowledge includes cultural self-awareness, as well as knowledge of others' cultures, languages, histories, and lived realities. Essential skills are listening, observing, reflecting, empathizing, and communicating. Attitudes, increasingly recognized as core to cultural competency, are those of curiosity, humility, open-mindedness, respect, and tolerance for not knowing (ambiguity). Janet Bennett, an interdisciplinary scholar and executive director of the Intercultural Communication Institute, summarizes the key cognitive competency as cultural self-awareness, the key behavioral as empathy, and the key affective as curiosity. ${ }^{8}$

A useful concept for understanding cultural competency is that of the continuum, developed initially by a team of social workers led by Terry Cross and later adapted by others. The continuum is a conceptual structure on which to locate possible personal and organizational behaviors. The Cross continuum sets cultural destructiveness, incapacity, and blindness on one end of the continuum; next resides precompetency or limited competency; and at the high end of the continuum is cultural competency and proficiency. Self-reflection or analysis, professional development, and personal cross-cultural experience progress individuals through the continuum. ${ }^{9}$ It is helpful, too, to visualize the tangible goals or recognizable characteristics of a culturally competent individual or system. Individuals display KSAs such as self-awareness, curiosity, humility, dexterity, and world-mindedness; they actively seek knowledge, professional and personal development, and interaction with varieties of cultures. Organizations demonstrate capacity to value diversity, conduct self-assessment, manage the dynamics of difference, acquire and institutionalize cultural knowledge, and adapt to the cultural contexts of individuals and communities they serve. Each of these elements needs to occur across all levels of any system. ${ }^{10}$ 


\section{Cultural Competency across Disciplines, with an Emphasis on Library and Information Science}

Cultural competency is well recognized in many fields and prominent among cultural diversity concepts. It has been so for decades. General benefits of its application in practice-based fields include improved service to clients, knowledgeable self and colleagues, improved reflective skills, and strategic use of (ever-present) human differences toward personal, organizational, and societal goals. Numerous professions, particularly those centered on human services, incorporate cultural competency. First applied in the United States in the health field, it evolved there among other intellectual structures and service methods to help address disparities related to the provision of health services. Psychology, social work, education, law enforcement, and other fields now employ this framework at individual and organizational levels to improve human services. And, cultural competency is found in the corporate world, located among global talent management and effectiveness, social responsibility, and inclusion work, where the strategic nature of it is well recognized. It is truly interdisciplinary. ${ }^{11}$

Cultural competency commands a presence within the field of library and information science/studies (LIS). As in other fields, this presence is most established within the discourse on equity, diversity, and inclusion (EDI) as well as occasionally in talent management and leadership, and it developed within the milieu of multiculturalism and diversity efforts. ${ }^{12}$ The American Library Association Policy Manual's "Positions and Public Policy Statements" Diversity section partners cultural competency with inclusion; defines it as "the acceptance and respect for diversity, continuing self-assessment regarding culture, and the ongoing development of knowledge, resources, and service models that work towards effectively meeting the needs of diverse populations"; and claims it critical to equitable service. ${ }^{13}$ As summarized by authors Patricia MontielOverall, Annabelle Villaescusa Nuñez, and Verónica Reyes-Escudero, “LIS professionals' interest in cultural competence followed many years of discussions about multicultural and diversity issues, for instance, recruiting minorities to the profession. Shifting demographics, increasing populations of immigrants and English-language learners (ELLs), and minorities with limited access to information became a cause for concern among LIS professionals beginning in the 1980s."14 "Culturally Competent Libraries," a 1994 article by library and organizational development consultant Kikanza Nuri-Robins, is the LIS field's first publication on the topic. ${ }^{15}$ Nuri-Robins connects cultural competency to organizational development, embraces the model of the continuum, and asserts the primacy of self-awareness. Nuri-Robins recognizes the nonthreatening nature of cultural competency, because it honors whatever place workers or an 
organization might occupy on the continuum. Furthermore, she articulates the nature of the framework as inward out-centered on the self, rather than on others. Relatedly, this framework relieves the minority members of a profession from the core of EDI work, instead placing the primary role and responsibility on those in the majority. ${ }^{16}$

Cultural competency in LIS was, and remains, most frequently discussed in area specializations and ethnic or identity affiliate groups, as well as in management and leadership literature due to connections with recruitment, public service modes, professional standards, and education. A cover spread and strong editorial in 1999's Library Journal report of the 4th National Conference of African American Librarians asserts a collective failure. "True cultural competence has rarely blessed our professional practice or even penetrated our professional consciousness," writes editor-in-chief John Berry, reminding readers of the library profession's history of expecting others to assimilate to the dominant paradigm. ${ }^{17}$ Other key articles in prominent American library journals followed. They emphasize various elements of the cultural competency framework.

A cross-disciplinary team comprised of a librarian and a faith community leader, Nancy Ottman Press and Mary Diggs-Hobson, published their experiences providing health information to a community "where they are, not where we want them to be.” They articulate some of cultural competency's knowledge, skills, and attitudes (KSAs) as applied to library work. According to this article, attitude begins with self-awareness and then extends to awareness of cultural heritage and context of others; self-assessment, and comfort with difference, are key elements, as are valuing identities and intersectionality. Knowledge in their context means librarians' awareness of systemic barriers affecting users and users' information-seeking requirements. Skills include cross-cultural communication abilities, building alternative roles for the librarian (such as ombudsperson or consultant), and honoring indigenous or existing information providers and systems. ${ }^{18}$

Medical librarian Misa Mi extends the requirement or prerequisite for cultural competency demanded in other professions to LIS, calling for similar requirement of librarians. ${ }^{19} \mathrm{Mi}$ also calls for action at leadership organizations: "National, regional, and local professional organizations should take initiatives in promoting cultural competent skills for library staff, sponsoring or developing cultural competence programs and C[ontinuing] E[ducation] courses, and compiling a bibliography to meet the needs of libraries and librarians for information about providing cultural competent services." ${ }^{20}$ Librarian and consultant Sandra Ríos Balderrama claims cultural competency as critical to libraries and reminds readers that learning and growth occur at the point of tension and conflict. Ríos Balderrama also notes the strategic benefit of cultural competency at both the personal and system levels: "Differences . . . offer new insights 
and the capability for deeper understanding. Differences offer outcomes that come out of synergy. Awareness of our cultural values and growing our cultural competence in order to interact effectively and respectfully across cultures are the first steps toward tapping into the richness of "multi."'21

Then in 2009, librarian and professor Patricia Montiel-Overall published "Cultural Competence: A Conceptual Framework for Library and Information Science Professionals,” an influential article providing a broad LIS vision for cultural competency. In it, she pens a definition for LIS that has been frequently cited and embraced by others:

Cultural competence is the ability to recognize the significance of culture in one's own life and in the lives of others; and to come to know and respect diverse cultural backgrounds and characteristics through interaction with individuals from diverse linguistic, cultural, and socioeconomic groups; and to fully integrate the culture of diverse groups into services, work, and institutions in order to enhance the lives of both those being served by the library profession and those engaged in service. ${ }^{22}$

This article provides other valuable insights. Montiel-Overall centers cultural competency in cultural psychology, which embraces mind and culture as inseparable. This differs from general psychology and indeed from the Western theoretical grounding widely embedded throughout LIS: the objectivist notions of knowledge and the behaviorist notions of learning through practice, training, and skills, wherein "mind and culture are separate." ${ }^{23}$ Montiel-Overall's model for LIS perpetuates the continuum, stresses the primacy of process, and introduces its three domains: the cognitive, the interpersonal, and the environmental. Domains are not exclusive of each other, and each can include its own continuum. Self-awareness and building cultural knowledge are located in the cognitive domain. The interpersonal domain includes cultural appreciation, caring, and matching our practice with our values. The environmental relates to understanding the environment, such as resources and assets (e.g., language and dialect) and systems and structures affecting the community. ${ }^{24}$ Though MontielOverall does not explicitly state it, current majority culture's ability-, class-, gender-, and racial-based systems belong within the environmental domain; an understanding of culture certainly demands recognition of power structures.

Cultural competency is established within LIS in Australia and New Zealand too, including in education and training. Australian librarian Fiona Blackburn writes that cultural competency is included in the policies and strategies of major institutions, and professional training programs incorporate it to various extents. ${ }^{25}$ LIS scholars Nicole Gaston, Alison Fields, Philip Calvert, and Spencer Lilley outline that in New Zealand, due to leadership at the national level by both the national LIS organization and Te Rōpū Whakahau (the national body that represents Māori engaged in libraries, culture, knowledge, information, 
communication, and systems technology), LIS sector workers "are expected to be able to competently engage with a wide variety of cultures. . . . The tapestry of social and cultural inclusion in New Zealand is being woven into all areas of the library and information profession in New Zealand, with initiatives seen in all areas of LIS education, the wider profession and in service to the communities and clients they serve." ${ }^{26}$ Furthermore, their successful model is in part due to the wider LIS field actively changing through incorporation of Māori, a nondominant culture. ${ }^{27}$

In the United States too, advocates are advancing cultural competency particularly in regard to professional training and development. The 2017 monograph by Professor Nicole A. Cooke, Information Services to Diverse Populations: Developing Culturally Competent Library Professionals, a text for LIS graduate students in the United States that provides graduate lesson plans and further readings, is also valuable for practitioners and those seeking professional development. Cooke reinforces and contextualizes the pertinent literature to date and, among other things, presents "counter-storytelling," a method to disrupt and democratize dominant narratives, as one element of culturally competent training. Cooke extends the concept of the continuum to that of a cycle, its movement regressive as well as progressive, explaining “. . . it might be even more useful to think of this development as a cycle, instead of a linear process, as cultural competence does not simply begin and end, it is an ongoing process ... [that] requires consistent work, and . . . it is possible to move backward on the scale. . . . ${ }^{28}$ Cooke highlights cultural humility within cultural competency, linking humility to improving power imbalance, and social justice work. ${ }^{29}$

Others call for embedding cultural competency into national formal education. Generally, scholars discuss cultural competency vis-à-vis professional education in the context of EDI and to address the scarcity of social justice and EDI content in the LIS classroom..$^{30}$ Professors Kafi Kumasi and Renee Franklin Hill recognize "a need to better infuse cultural competence learning objectives into the LIS curriculum" and that deliberate cultural competency standards would improve outcomes and assessment. ${ }^{31}$ Outreach librarian Alexandra Rivera presents cultural competency as a method to right the LIS field's minimal efforts to address foundational issues of racism and disparities within research and service, and promotes LIS programs that develop skills of contextual inquiry in students. Rivera reiterates the "virtuous circle" introduced by scholars Paul Jaeger and Renee Franklin wherein a diverse faculty, and curriculum that is based in cultural competency, foster diversity within students, faculty, and by extension the profession at large. And Rivera extends responsibility for the development of cultural competency from graduate education to the wide LIS ecosystem, including work organizations and professional standards. ${ }^{32}$ 
Specialized librarian groups emphasize cultural competency in professional standards, or note it as critical to LIS training. The standards developed by the Association for College and Research Libraries in 2012 underscore cultural competency by centering it in the title, Diversity Standards: Cultural Competency for Academic Libraries, and stressing key elements such as the primacy of self-awareness and its dynamic nature. ${ }^{33}$ The Young Adult Library Services Association included cultural competency throughout a 2014 report, and the 2015 Competencies for Librarians Serving Children in Public Libraries names cultural competency in areas ranging from service to professionalism and professional development. ${ }^{34}$ The Association of College and Research Libraries/American Library Association Task Force on Core Competencies for Special Collections Professionals invokes the spirit of cultural competency in a few areas of its Guidelines; however, it does not clearly connect these competencies to the cultural competency framework. For example, Fundamental Competency 3 guides a practitioner to "[possess] cultural and linguistic competencies appropriate for their collections and user communities.” And the specialized category of management, supervision, and leadership states that employee professional development is to include the cultural context to one's work..$^{35}$

The LIS literature invites dialogue among specialty fields and cognate professions. Montiel-Overall called for such in her 2009 article, noting that development of cultural competency in LIS requires broad discussion and exploration of how to best develop it among different areas of the profession. ${ }^{36}$ Others issue a similar invitation. In Where Are All the Librarians of Color?: The Experiences of People of Color in Academia, a book that provides space and voice to archivists of color and affirms the close relationship between the archival profession and that of librarianship, archivist Rebecca Hankins and librarian Miguel Juárez state an urgent call for such broad discussion regarding EDI. "Diversity is not a settled issue that we can move on from to other concerns. . . . [it is] the most consequential and important issue of our time," they write, encouraging a large body of research and publication within the library and archives professions. ${ }^{37}$ And the authors of Latinos in Libraries, Museums, and Archives: Cultural Competence in Action! An Asset-based Approach “. . . invite library, museum, and archive professionals to consider a number of issues. How can cultural competence be developed? How is cultural competence to be evaluated? Should cultural-competence guidelines recommended by one group within the profession apply to the entire profession? To what extent is cultural competence incorporated into the curriculum of LIS schools?"38 Such invitation to pan-professional conversation recognizes the inherent strength that lies in the differences within LIS, and it prompts a close study of the archival profession. 


\section{Review of Archival Literature}

To explore the extent to which the archival profession in the United States is engaging with cultural competency, I conducted a literature review. I searched databases and read broadly, including in critical archival studies, surveying for any uses of the phrase (or like phrases); I then analyzed any use thereof. ${ }^{39}$ I next reviewed four prominent peer-reviewed English-language archival journals. My survey of the journals American Archivist, Archives \& Records, Archival Science, and Archivaria reveals that cultural competency has been occasionally discussed since 2009, and, with only one exception, these discussions take place in American Archivist.

American Archivist articles and book reviews regarding cultural competency appear within the last five years. ${ }^{40}$ And Dennis Meissner's 2016 presidential address provides the first frank exploration of cultural competency, including the first definition to appear in print in archival literature. Meissner also stressed the importance of its highly individualized work; "[b]efore we attempt to diversify SAA or the archival record, we need to rotate the lens and work on ourselves as SAA members. The way to begin doing this is through increasing our cultural competence as the first step in making us more inclusive individuals." ${ }^{41}$ This speech was published alongside Chris Taylor's "Getting Our House in Order: Moving from Diversity to Inclusion," an article exploring the internal work necessary to succeed with intercultural competency. Taylor's was the first article in the journal to use "intercultural competency" as a keyword. In 2017, American Archivist included a book review by Margarita Vargas-Betancourt of Latinos in Libraries, Museums, and Archives: Cultural Competence in Action! An Asset-based Approach. Three other articles published in the journal since 2013 include the phrase or a near variation. While these three certainly reference cultural competency, they do not discuss it substantially or explore the meaning of the framework for archivists. ${ }^{42}$

The first article within the four journals to reference cultural competency appeared in 2009 in Archival Science. ${ }^{43}$ Scholar Kelvin White includes the examination of an archival educator's own cultural competency as a key element within the Reflexivity component of his proposed framework for Mexican archival education. White explains "that educators may realize that they need to gain cultural competency (as much as is possible, permitted or appropriate without causing disrespect) by spending time with community members to learn about the object of knowledge and gain a richer and more comprehensive understanding of the group's perspective." 44 This discussion of cultural competency is the only one in Archival Science (and its predecessor Archives and Museum Informatics). In my review of the other two journals, Archivaria ${ }^{45}$ and Archives 8 Records (and its predecessor Journal of the Society of Archivists), ${ }^{46}$ I located no discussions of cultural competency. 
Outside of these publications, a few others address cultural competency vis-à-vis archives or special collections. A 2010 article by Rebecca Hankins and Miguel Juárez in the journal Art Documentation asks questions and provides answers for archival practice, in this case for the broadening and strengthening of art collections. The authors stress the need for formal mission statements and collecting policies, as these provide a public and strong statement, and give "weight" to efforts at cultural competence. ${ }^{47}$ The book Latinos in Libraries, Museums, and Archives, published in 2017, includes archives in its title, in its general intent, and in a chapter by curator Veronica Reyes-Escudero on special collections and archival work. There, Reyes-Escudero explores archival functions through the lens of Latinx cultural competency and offers professional characteristics of such. These include some of the KSAs discussed above: awareness of one's own culture; appreciating others; the ethic of caring, understanding situational context; and historical factors; and language fluencies. ${ }^{48}$ This book affirms power-sharing with community. Furthermore, its unique contribution to cultural competency literature is the thoughtful presentation of asset-based thinking, wherein one considers users' contributions more than their needs:

It refocuses cultural competence from a deficit model to an asset model. ... An asset-based model focuses on what is right in communities and builds programs, services, policies, legislation, and funding around community strengths. In our suggested model, community members are actively involved in the delivery of services. Deficit models focus on the negative aspects within communities, and members are not participants, but beneficiaries, of services. ${ }^{49}$

Latinos in Libraries, Museums, and Archives provides a collaborative pan-professional message, and, as noted above, invites conversation among related fields. Furthermore, the authors urge action, as fitting the spirit of cultural competency: "If cultural competence is to become widespread, however, . . . staff should not wait for it to be regulated [through professional guidelines and educational systems]. Each individual and institution in the profession can play a role in moving cultural competence forward." ${ }^{50}$ And, in 2018, archivist Mark Shelsted published a case study on an institutional application of cultural competency, in which he and colleagues "tailored" archival work to circumstances that in turn led to engaged users, including a local community that recognizes the institution as providing access to archives "for a more nuanced understanding of . . . history." 51

With this relatively small catalog of archives-specific published discourse on cultural competency, it is useful to consider the wider archival literature. As noted above, cultural competency resides often within equity, diversity, and inclusion work in many professions; I place it here for the archival profession, as well. Yet cultural competency, and EDI, are examples of the many cross- or interdisciplinary developments affecting the profession. Others include critical theory, cultural relativism, ethnic and feminist studies, globalization, 
indigenous knowledge, postcolonialism, postmodernism, the rights and justice movements, and developments within education, leadership, management, and technology. As summarized by scholars Kelvin White and Anne Gilliland, “. . . archival studies today transcends the professional field of archival science. It encompasses an ever-broadening array of disciplinary discussions and methodological approaches that are identifying, critiquing, and addressing the shifting social, cultural, philosophical, and political, as well as the technological, imperatives of record keeping and remembering in the twenty-first century." 52

Generally, archival principles, values, and practice are developing and expanding from the foundational to allow for pluralism and alternatives to address the social and cultural aspects of archival activity. ${ }^{53}$ This maturation was and is affected by critical theory. Critical theory questions assumptions and practices through an ethical or political lens. It identifies, for example, systems of power that are historically racist and sexist and protective of the dominant. ${ }^{54}$ Critical archival studies, by extension, as defined by authors Michelle Caswell, Ricardo Punzalan, and T-Kay Sangwand, examines the relationship between archives and oppression/liberation. It works to “. . . (1) explain what is unjust with the current state of archival research and practice, (2) posit practical goals for how such research and practice can and should change, and/or (3) provide the norms for such critique. In this way, critical archival studies, like critical theory, is emancipatory in nature, with the ultimate goal of transforming archival practice and society writ large." ${ }^{55}$ One example of a changing archival concept influenced by critical theory is the expansion of the principle of provenance beyond record creators to one that can include the "subjects" of the records, their curators, and users. ${ }^{56}$

Critical theorists, and critical librarian and archival studies, provide thought-provoking context for cultural competency, though this is yet to be fully explored. For example, scholar Todd Honma does not speak directly to cultural competency yet critiques celebration of difference and promotion of cross-cultural understanding as "empty of critical analyses of race and racism that instead adopts a commodified diversity management more in line with capitalist market relations than emancipatory anti-racist struggles." ${ }^{57}$ And Kelvin White has more recently explored the role of culture and archives, though he does not explicitly discuss cultural competency. In a chapter titled "Race and Culture: An Ethnic Studies Approach to Archival and Recordkeeping Research in the United States," White argues that the role of culture is key to understanding the interacting dynamics of race, archives, and power. White centers culture within records: "What shapes archival processes and concepts? Culture. What is remembered or recorded is shaped by culture. The archive's form is shaped by culture. ..." 58 
Other LIS authors clearly link cultural competency and critical theory. David James Hudson, writing with a critical theory lens, appraises cultural competency as a form of liberal antiracism wherein LIS workers individualize racism in a primary goal to create "a heterogeneous harmony that represents respectful working conditions characterized by tolerance and minimal conflict." ${ }^{99}$ Hudson asserts that LIS's favoring of the individualistic is superficial and problematic. This is a useful critique, as it calls for assessment of cultural competency to ensure it is not a method wherein those in the dominant system can feel comfortable by simply discussing the personal, rather than working consistently toward meaningful change or dismantling a harmful system. Critical archives scholars may concur, due to the strong aspect of self within cultural competency. Archival critical scholars do address reflexivity; as noted by J. J. Ghaddar, Caswell and Punzalan have called for moving beyond rights-based rhetoric and "notions of archival pluralism and a liberal politics of recognition that emphasizes inclusivity, multiplicity, and self-reflexivity" because of its ineffectiveness. ${ }^{60}$ Ghaddar and others find self-reflexivity problematic, for it is "a mechanism for transforming guilt into shame, and bad feelings into good," and "serves to reinstitute the colonial structural domination it ostensibly seeks to disavow." 61

Other commentators find confluence with critical theory, while affirming cultural competency's still-nascent status. The authors of Latinos in Libraries, Museums, and Archives note that critical race theory and Latinx critical theory may not be common in discussions in the cultural competency literature, yet these explain underlying biases and policies behind cultural inequities in our systems and are indeed pertinent to cultural competency. ${ }^{62}$ In a journal recognized for furthering and pushing the critical dimension to LIS work, ${ }^{63}$ Blackburn explores cultural competency, whiteness, and intersectionality, recognizing that self-awareness can lead to awareness of the privilege inherent in dominant culture. "Privilege, while not explicitly referenced in cultural competence theory, is implicit in how culture works; whiteness, again not explicitly referenced in cultural competence theory, is central in Western library structures and operations. . . . If the starting point of cultural competence is an understanding of the role of culture in your life (including your workplace), and in the lives of others, then you will also become aware of ... privilege and marginalization. ..." ${ }^{44}$ Awareness of personal privilege, biases, as well as systemic inequity, fit squarely in the KSAs.

Another area of confluence may be found in the ethics of care. Cultural competency developed within the fields of care providers. Curator ReyesEscudero includes "an ethic of caring" in a list of culturally competent qualities, ${ }^{65}$ and Montiel-Overall explains that one develops "cultural appreciation and an ethic of caring" in the interpersonal domain of cultural competency. ${ }^{66}$ What relationship does cultural competency have to the "ethics of care" introduced 
by scholars Punzalan and Caswell as a suggested alternative or departure from rights-based archives work? Ethics of care stress that people are linked through webs of responsibilities and emphasize (among other things) connection and context. This feminist framework honors "relationships of mutual obligation that are wholly dependent on culture and context." ${ }^{67}$ Upon further development, this may be more closely related to cultural competency skills and attitudes than currently articulated. This possible synergy is one example of the many areas where the profession would benefit from deeper consideration and more published literature on the relationships of cultural competency and archival theory, and cultural competency and practice.

\section{The Archives Profession in Action}

Beyond the literature, in practice and in public discussion, archivists are engaging with cultural competency. Practitioners and leaders are reflecting on self, recognizing the role of culture, and acting on such to improve services, relationships, and organizations. The formal national leadership of the Society of American Archivists (particularly Council, complemented by committees and component groups) provides notable and likely the earliest public discussion on cultural competency in the profession. Having for many years designated diversity (and later, diversity and inclusion) as a major issue of and for the profession, ${ }^{68}$ SAA Council first acted on cultural competency within this context. In 2009, it directed a subgroup to "revisit and reword the activities associated with the [Strategic Plan's] Diversity Priority, Outcome \#4, which dealt with issues of retention and diversifying the profession." This subgroup thus produced action $(\mathrm{C})$, to "[d]evelop a cultural competencies framework as it relates to archivists and the archives profession," and Council approved. The subgroup's support statement for action $(C)$ directed a "series of concrete tools, training, and practical steps . .." for members. ${ }^{69}$ Rebecca Hankins, then on Council and the subgroup, reflects that some of this activity was a result of many years' discourse on cultural sensitivity and particularly the Protocols for Native American Archival Materials, which itself provided a catalyst to confront the fact that the American profession was not yet making meaningful progress on diversity and inclusion issues. Council thought it wise to break this seemingly behemoth issue of EDI out to smaller areas of action (e.g., the Mosaic scholars, developing programming). As noted by Hankins, “. . . the reality is you have to parse it out and then do something."

In the decade following, Council member Helen Wong Smith provided key leadership for cultural competency in SAA, likewise recognizing the need to work within a manageably sized area and suggesting a concentration on cultural competency. ${ }^{71}$ This initiative then gained momentum, and Wong Smith offered training 
to SAA Council and staff, developed educational opportunities, and presented to membership. She and colleagues also worked via component groups, such as the Archives and Archivists of Color Roundtable, and affiliated or colleague organizations such as the Midwest Archives Conference and San Jose State Student Chapter. ${ }^{72}$ SAA continued efforts with Wong Smith and provided further resources for membership, namely educational resources on cultural diversity competency, ${ }^{73}$ and by doing so is meeting Mi's call for sponsored education.

At the national conference level, archivists are likewise very recently discussing cultural competency. SAA Annual Meeting educational sessions reflect the interests, skills, and action areas of members, as members provide proposals and develop the content for them. As measured through use of the phrase (and again, its variation) in the printed preliminary program, ${ }^{74}$ archivists discussed cultural competency at least twice at the 2017 Annual Meeting. Wong Smith presented “Cultural Diversity Competency's Role in Diversity, Inclusion and Community Engagement" at the Research Forum, and four members developed a session "to engage topics of culturally competent archival work" and intentionally referenced the phrase in its title. ${ }^{75}$ The first appearance of the phrase within the preliminary program occurred one year earlier with the description for a session regarding whiteness in the profession: “. . . a collaborative and engaging conversation that complements SAA's ongoing efforts toward cultural competency, diversity, and inclusion" and noting Council's "Initiative for Cultural Diversity Competence." ${ }^{\prime 6}$ And a graduate student project poster in 2015 highlighted the phrase itself and cited Montiel-Overall's influential LIS article. ${ }^{77}$ All these indicate members' engagement with cultural competency.

SAA's formal leaders also provided key annual conference visibility for cultural competency in recent years. The 2016 presidential address by Meissner and companion keynote by Chris Taylor are important as oral presentations at this venue, as they are also important in their later published forms in American Archivist. Wong Smith formally introduced SAA Council's initiative on cultural competency to the membership in 2015 during the Leadership Plenary hosted by president Kathleen Roe. Wong Smith here also illustrated the continuum, introduced skill levels, and invited members "to join Council in adopting the precepts of Cultural Diversity Competency and experience the benefits it brings to you, your collections, and your communities."78

In daily practice archivists are engaging in culturally competent work based in self-cultural awareness and incorporating empathy, humility, care, and support for a variety of cultural norms. Such work can be placed toward the competent end of the continuum should archivists and their organizations apply the cultural competency framework. This practice, appearing within the milieu of the broader movements and intellectual developments discussed above, can be found across the various archival functional areas. In acquisition and collection development, 
for example, archivists broadened collections in connection with the mid-twentieth-century demand for social, public, local, and identity-based histories, and increasingly archivists support others in community-based archival work, in complement to institutional control and ownership. ${ }^{79}$ Appraisal theory and practice always demanded recognition of context of creation as well as of the creators themselves; a stronger emphasis on culture, a form of context, thus fits well into traditional appraisal. The emphasis on "self" within cultural competency fits squarely into newer concepts, such as archival agency, dominant paradigms, and reflexivity, that are affecting appraisal and other core functions.

In description, archivists are working to evolve or disrupt current systems and norms by way of crowdsourced, iterative, multilingual, or culturally conscious descriptive practice. ${ }^{80}$ Participatory and restorative archival description reveals that archivists are listening critically to their-and their predecessors'-agency within descriptive tools, and they are giving space to and amplifying plural voices/ cultures within materials described. One example is the conscious description articulated by archivist Dominique Luster in the Teenie Harris Archive. This work is, in part, an effort to "elevate humanity back into our archival records through description." ${ }^{81}$ Furthermore, the management of the whole project surrounding the Teenie Harris photograph collection "was shaped by an advisory committee... who insisted on the African American community's ownership of the history represented in Harris images. Consequently, the archive catalog is based on first-person accounts by Harris's subjects and contemporaries. . .." The photograph collection description thus includes content contributed by the public or contemporary news publications.$^{82}$ Luster's work acknowledges the power and control inherent in archival description and provides an almost arithmetic formula for description including elements of cultural competence attitudes: kind, compassionate, mindful, empowering, respectful, and inclusive description = "conscious."

In an example from my own experience with outreach and professional development, the Immigration History Research Center Archives-where staff and institutional identity in many ways fit the field's dominant demographic and culture, and which seeks to work reciprocally with community-accepted an offer from Abdi Roble, a Somali American documentary photographer and community archivist, to work with him on community-based archiving. Throughout a resulting yearlong residency that benefited all parties, our organization reflected on archives in relation to cultures and lived realities of individuals and various communities, including Somali American. I became acutely aware of how some potential users and donors react to the archival use of the verb "document" and the noun "documentation," and we discussed what collection management tool works for indigenous knowledge systems. Roble stressed to us the importance of recognizing how records creators, or people who can be located within archival records, view such records of themselves. ${ }^{84}$ 
The year also provided ample opportunity for me to apply the framework of cultural competency to both myself and to my organization. For example, we were invited to contribute to a community discussion on archives. The location of the event and the role for the archives were unusual for us, as typically we invite community groups onto our campus and into our archives, and we provide expertise. In this case, we accepted an invitation to play a different role, that of supporter, and off-campus. With this event, I applied KSAs. Knowledge included self-reflection through which I recognized a personal value that intersected with a cultural bias; skills included empathy and listening closely while communicating; attitude included comfort with ambiguity. I approached the event recognizing community as expert and asset in regard to archival work. The archives supported existing information providers and locations, as called for by Press and DiggsHobson. ${ }^{85}$ This experience was simply part of a process; more (and continual) work is needed to be culturally competent. Applying the continuum to my experience, I place myself in some aspects moving from cultural blindness to awareness, and in others from awareness to competence. This movement is illustrated by the curved arrows in Figure 1. Figure 1 depicts the continuum developed by Cross et al., later adapted by Montiel-Overall et al. and incorporates Cooke's concept of the possibility of progression and regression, illustrated here by the bidirectional arrows.

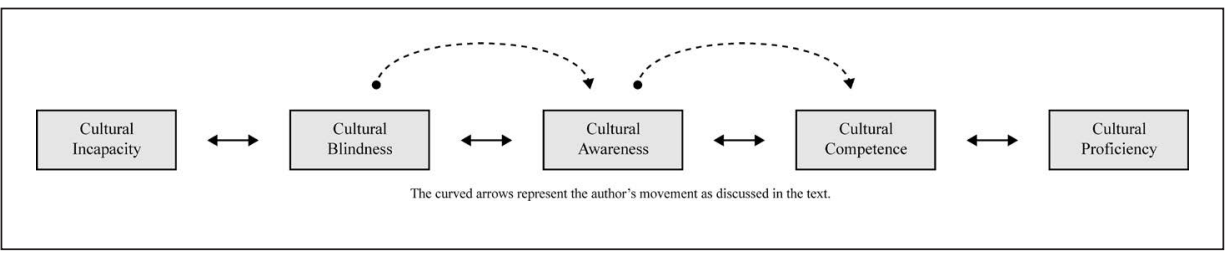

FIGURE 1. Author's adaptation of the cultural competency continuum ${ }^{86}$

These practices, and others like them, provide useful models of cultural competency within archival work and will help to develop cultural competency as a framework for LIS.

\section{Conclusion}

Thus, archivists can contribute to LIS development of cultural competency. As introduced in this article, archival theory and practice in many ways work well with the framework. Archival perspectives on access and outreach, collection development and appraisal, description, and more can help build a varied and thus useful LIS-centered framework. Further research and analysis are needed to realize the full contribution, as well as to help the archival profession mature in its work with cultural competency. 
This article posits that cultural competency is one framework available to all archivists to advance equity and inclusion within the profession. The framework is accessible and easily applied. Based in self- or organizational awareness, and complemented by building wider cultural knowledge, it can be particularly constructive for dominant-culture archivists and librarians. The archival profession, comprised largely of members of a dominant majority, ${ }^{87}$ is well suited to and in need of cultural competency because of this starting point of self-reflection and analysis. As articulated by the many authors summarized in this article, the framework offers many benefits. And it is nonthreatening, supportive of each person's incremental movement regardless of location along the continuum or work environment. The inward-out dimension encourages action from ourselves rather than from others, and I found it empowering for moving beyond discussion to action and leveraging human difference. In Archives Power: Memory, Accountability, and Social Justice, Randall Jimerson reminds readers of the strength that comes from the great variety within the archival profession and the fact that archivists have many valid options for "responding to the call of justice," 88 a comment that shares with cultural competency a spirit of openness and recognition of individual work. This study of emerging cultural competency reveals archivists thinking and practicing with humility and self-reflection, and strategically managing across difference. In doing so, they are developing "next practice" out of "best practice" 89 and responding to the call.

\section{Notes}

The author gratefully acknowledges the many people who discussed this topic and reviewed the article.

1 Janet M. Bennett, The SAGE Encyclopedia of Intercultural Competence (Thousand Oaks, Calif: SAGE Publications, Inc., 2015), 217, http://dx.doi.org/10.4135/9781483346267. All terms describe the capacity to interact effectively and appropriately across cultures. I have chosen to use "cultural competency" because it is the phrase most common in library and information science (LIS) and social work, and because it is one of the shorter phrases. The Society of American Archivists, as discussed elsewhere in this article, often uses "cultural diversity competency." All of these reflect Anglophone and Euro-American-centric understandings of the phrases; again see Bennett, The SAGE Encyclopedia of Intercultural Competence, 217.

2 Bennett, The SAGE Encyclopedia of Intercultural Competence, 217. Emphasis mine.

3 Dennis Meissner, "Bare Necessities (Presidential Address)," American Archivist 80, no. 1 (2017): 8. The SAGE Encyclopedia of Intercultural Competence definition is "communication and behavior that are both effective and appropriate in intercultural interactions, with effectiveness referring to the degree to which the individual's goals are achieved and appropriateness referring to the manner and context in which those goals are achieved." Bennett, The SAGE Encyclopedia of Intercultural Competence, 218.

4 Bennett, The SAGE Encyclopedia of Intercultural Competence, 549.

5 Patricia Montiel-Overall, Annabelle Villaescusa Nuñez, and Verónica Reyes-Escudero, Latinos in Libraries, Museums, and Archives: Cultural Competence in Action! An Asset-Based Approach (Lanham, Md.: Rowman \& Littlefield, 2016), 22, for example. And archivists and cultural heritage professionals may find of particular interest this portion of a classic 1952 definition of culture by A. L. Kroeber and C. Kluckhohn: "Culture consists of patterns, explicit or implicit, of and for behavior acquired 
and transmitted by symbols, constituting the distinctive achievements of human groups, including their embodiments in artifacts. . . " quoted in Michàlle E. Mor-Barak, Managing Diversity: Toward a Globally Inclusive Workplace (Thousand Oaks, Calif.: Sage Publications, 2005), 169.

6 Montiel-Overall, Nuñez, Reyes-Escudero, Latinos in Libraries, Museums, and Archives, 23; Terry L. Cross et al., Towards a Culturally Competent System of Care (Washington, D.C.: CASSP Technical Assistance Center, 1989), 13; Michael L. Wheeler, "Inclusion as a Transformational Diversity and Business Strategy, " in Diversity at Work: The Practice of Inclusion, ed. Bernardo M. Ferdman (San Francisco: Willey, 2014), 553.

7 Many authors supply characteristics that I am summarizing here. See for example Nancy Ottman Press and Mary Diggs-Hobson, "Providing Health Information to Community Members Where They Are: Characteristics of the Culturally Competent Librarian,” Library Trends 53, no. 3 (2005): 407.

8 Bennett, The SAGE Encyclopedia of Intercultural Competence, 218-19; Janet M. Bennett, "Intercultural Competence: Vital Perspectives for Diversity and Inclusion," in Diversity at Work: The Practice of Inclusion, 157-60.

9 Cross et al., Towards a Culturally Competent System of Care, 13-18; Patricia Montiel-Overall, "Cultural Competence: A Conceptual Framework for Library and Information Science Professionals," Library Quarterly 79, no. 2 (2009): 186-87.

${ }^{10}$ Cross et al., Towards a Culturally Competent System of Care, 19-21; Georgetown University National Center for Cultural Competence, “Conceptual Frameworks/Models, Guiding Values and Principles," https://nccc.georgetown.edu/foundations/framework.php.

${ }^{11}$ Summaries can be found in Ransford Danso, "Cultural Competence and Cultural Humility: A Critical Reflection on Key Cultural Diversity Concepts,” Journal of Social Work 18, no. 4 (2018) (this work also provides useful restatement of critique, as well as a defense of, cultural competency within social work); Kafi D. Kumasi and Renee F. Hill, "Examining the Hidden Ideologies within Cultural Competence Discourses among Library and Information Science (LIS) Students: Implications for School Library Pedagogy,” School Libraries Worldwide 19, no. 1 (2013): 130; Bennett, The SAGE Encyclopedia of Intercultural Competence, 217; Montiel-Overall, "Cultural Competence," 18487; Nicole A. Cooke, Information Services to Diverse Populations: Developing Culturally Competent Library Professionals (Santa Barbara, Calif.: Libraries Unlimited, 2017), 15. For summaries of interdiscipline, see Bennett, “Intercultural Competence: Vital Perspectives," 157-58, and Cooke, Information Services, 15.

${ }^{12}$ Cooke, Information Services, 16-17. As an example of its current firm footing within LIS, see Toni Anaya and Charlene Maxey-Harris, "Diversity and Inclusion, SPEC Kit 356" (September 2017), Association of Research Libraries, http://publications.arl.org/Diversity-Inclusion-SPEC-Kit-356. The Executive Summary states, "The increase of published literature about cultural competencies, microaggressions, and assessment of diversity issues, as well as the inclusion of social justice movements in libraries, suggests diversity-related activities have increased and evolved over the last seven years." For more on the development of cultural competency within library and information science, see for example Montiel-Overall, Nuñez, and Reyes-Escudero, Latinos in Libraries, Museums, and Archives, chapter 1. On the longer history of EDI in LIS, see for example these works and their sources: Shaundra Walker, "Critical Race Theory and Recruitment, Retention and Promotion of a Librarian of Color: A Counter-Story," in Where Are All the Librarians of Color? The Experiences of People of Color in Academia, ed. Rebecca Hankins and Miguel Juárez (Sacramento: Library Juice Press, 2015); Maurice B. Wheeler, Unfinished Business: Race, Equity, and Diversity in Library and Information Science Education (Lanham, Md.: Scarecrow Press, 2005), chapter 1; Rosemary Du Mont, Lois Buttlar, and William Caynon, Multiculturalism in Libraries (Westport, Conn.: Greenwood Press, 1994), chapter 2.

${ }^{13}$ American Library Association, “ALA Policy Manual” (August 4, 2010), http://www.ala.org/aboutala/ governance/policymanual/updatedpolicymanual/tableofcontents.

${ }^{14}$ Montiel-Overall, Nuñez, and Reyes-Escudero, Latinos in Libraries, Museums, and Archives, 25.

${ }^{15}$ Montiel-Overall, Nuñez, and Reyes-Escudero, Latinos in Libraries, Museums, and Archives, 25.

${ }^{16}$ Kikanza Nuri-Robins, “Culturally Competent Libraries,” California State Library Foundation Bulletin 46 (January 1994): 8-15.

${ }^{17}$ John N. Berry, “Culturally Competent Service,” Library Journal 124, no. 14 (1999): 112. 
${ }^{18}$ Press and Diggs-Hobson, "Providing Health Information to Community Members Where They Are," 398, 407-8. For example, "Who should provide the information? Not the librarian; instead, community leaders, pastors, health professionals, and volunteers have the direct information-sharing role. The librarian is critical but in the background," 398.

${ }^{19}$ Misa Mi, “Cultural Competence for Libraries and Librarians in Health Care Institutions," Journal of Hospital Librarianship 5, no. 2 (2005): 19.

${ }^{20} \mathrm{Mi}$, "Cultural Competence for Libraries and Librarians in Health Care Institutions," 20.

${ }^{21}$ Sandra Ríos Balderrama, "The Role of Cultural Competence in Creating a New Mainstream," Colorado Libraries 32, no. 4 (2006): 8.

${ }^{22}$ Patricia Montiel-Overall, "Cultural Competence: A Conceptual Framework for Library and Information Science Professionals,” Library Quarterly 79, no. 2 (2009): 189-90.

${ }^{23}$ Montiel-Overall, "Cultural Competence,” 180-81.

${ }^{24}$ Montiel-Overall, "Cultural Competence,” 190-98.

${ }^{25}$ Fiona Blackburn, “The Intersection between Cultural Competence and Whiteness in Libraries," In the Library with the Lead Pipe (2015), Introduction.

${ }^{26}$ Nicole M. Gaston et al., "Raranga te kete aronui: Weaving Social and Cultural Inclusion into New Zealand Library and Information Science Education," in Perspectives on Libraries as Institutions of Human Rights and Social Justice, ed. Ursula Gorham, Natalie Greene Taylor, Paul T. Jaeger (Bingley, U.K.: Emerald, 2016), 391, 394.

${ }^{27}$ Gaston et al., "Raranga te kete aronui,” 394.

${ }^{28}$ Cooke, Information Services, chapter 6 discusses counterstorytelling, quote on page 18.

${ }^{29}$ Cooke, Information Services, 19-20.

${ }^{30}$ Kafi D. Kumasi and Renee F. Hill, "Are We There Yet? Results of a Gap Analysis to Measure LIS Students' Prior Knowledge and Actual Learning of Cultural Competence Concepts," Journal of Education for Library and Information Science 52, no. 4 (2011): 252. The concern regarding lack of diversity training in LIS is summarized by Cooke, "Information Services," 87, for example. For more on EDI in LIS higher education, see Wheeler, Unfinished Business, part 3; Paul T. Jaeger, John Carlo Bertot, and Mega Subramaniam, "Preparing Future Librarians to Effectively Serve Their Communities,” Library Quarterly 83, no. 3 (2013): 243-48.

${ }^{31}$ Kumasi and Hill, "Are We There Yet?," 260.

${ }^{32}$ Alexandra Rivera, "Indigenous Knowledge and Cultural Competencies in the Library Profession: From Theory to Practice,” 1-2, 7-8, IFLA WLIC 2013 Singapore, http://library.ifla.org/275/1/125rivera-en.pdf.

${ }^{33}$ Association of College and Research Libraries, "Diversity Standards: Cultural Competency for Academic Libraries” (American Library Association, May 4, 2012).

${ }^{34}$ Association for Library Service to Children, Competencies for Librarians Serving Children in Public Libraries, ALSC Education Committee, 1989, revised 1999, 2009, 2015; Young Adult Library Services Association (YALSA), The Future of Library Services for and with Teens: A Call to Action, http://www.ala. org/yaforum/sites/ala.org.yaforum/files/content/YALSA_nationalforum_final.pdf; see also YALSA, “Cultural Competence,” http://wikis.ala.org/yalsa/index.php/Cultural_Competence.

${ }^{35}$ Rare Books and Manuscripts Section, ACRL/ALA Task Force on Core Competencies for Special Collections Professionals, Guidelines: Competencies for Special Collections Professionals, Association of College \& Research Libraries (July 1, 2008 with revision dated March 6, 2017). These explicitly include archivists (e.g., "By deciding what or what not to collect, librarians and archivists actively participate in the preservation of intellectual and cultural history"; "The following key areas of skills and practice should form a knowledge base common to all special collections professionals.") In addition, the Guidelines cite SAA documents and refer readers to archival-library interassociational collaborations.

${ }^{36}$ Montiel-Overall, "Cultural Competence," 198-99.

${ }^{37}$ Hankins and Juárez, Where Are All the Librarians of Color?, 1.

${ }^{38}$ Montiel-Overall, Nuñez, and Reyes-Escudero, Latinos in Libraries, Museums, and Archives, xii.

${ }^{39}$ A search for terms that express related work (e.g., cultural sensitivity, diversity, documentation strategy, ethics, postmodernism, social justice, traditional knowledge) yields many results with 
interesting connections to be explored. Though these did inform my general perspective on cultural competency, I considered them beyond the bounds of this article.

${ }^{40}$ I conducted a keyword search within the electronic versions of American Archivist dated 1938 through 2017 (that is, all published issues at the time of writing this article) via http:/ americanarchivist.org/search/advanced. A search for phrases cross-cultural competency, cross-cultural competencies, cultural diversity competency, cultural diversity competencies, global mindedness, international mindedness yielded no results; inter-cultural yielded one use without pertinence. Intercultural competence was used in the journal twice: in "Bare Necessities" by Meissner and "Getting Our House in Order: Moving from Diversity to Inclusion" by Taylor. Taylor also used the phrase intercultural competency. Cultural competence yielded three pertinent uses: Meissner's "Bare Necessities"; and, from the fall/winter 2017 issue, an important book review of Latinos in Libraries, Museums, and Archives by Margarita Vargas-Betancourt; and the editor's farewell essay referencing same. A search for cultural competency revealed three uses: in the Vargas-Betancourt book review of Latinos in Libraries, Museums, and Archives; in "Documenting Regional Latino Arts and Culture: Case Studies for a Collaborative, Community-Oriented Approach" by Tracy Grimm and Chon Noriega; and in "Pinkett's Charges: Recruiting, Retaining, and Mentoring Archivists of Color in the Twenty-First Century" by Alex Poole. Cultural competencies appeared only in "Collaborations between Tribal and Nontribal Organizations: Suggested Best Practices for Sharing Expertise, Cultural Resources, and Knowledge" by Elizabeth Joffrion and Natalie Fernández; and Council discussion of August 2009.

${ }^{41}$ Meissner, "Bare Necessities," 6-18, quote on page 8.

${ }^{42}$ Tracy Grimm and Chon Noriega, "Documenting Regional Latino Arts and Culture: Case Studies for a Collaborative, Community-Oriented Approach," American Archivist 76, no. 1 (2013): 106; Elizabeth Joffrion and Natalia Fernández, "Collaborations between Tribal and Nontribal Organizations: Suggested Best Practices for Sharing Expertise, Cultural Resources, and Knowledge,” American Archivist 78, no. 1 (2015): 220; Alex H. Poole, "Pinkett's Charges: Recruiting, Retaining, and Mentoring Archivists of Color in the Twenty-First Century,” American Archivist 80, no. 1 (2017): 106.

${ }^{43}$ I searched Archival Science dated 2001 through 2018 and its predecessor, Archives and Museum Informatics, dated 1987 through 1999 (issues dated 2000 were not found), via the SpringerLink database and its search engine provided by the University of Minnesota Libraries. Searches for the following yielded no results: cross-cultural competency, cross-cultural competencies, cultural diversity competency, cultural diversity competencies, global mindedness, international mindedness, intercultural competency, intercultural competencies. Inter-cultural yielded one result; I concluded this use did not have direct pertinence. Cultural competence, cultural competency, and cultural competencies were each used in only one article: Kelvin L. White, "Meztizaje and Remembering in Afro-Mexican Communities of the Costa Chica: Implications for Archival Education in Mexico," Archival Science 9, nos. 1-2 (2009): 43-55, discussed in article text.

${ }^{44}$ White, “Meztizaje and Remembering," 52.

${ }^{45}$ I searched Archivaria via the portal offered by the Association of Canadian Archivists at https:// archivaria.ca/index.php/archivaria/issue/archive, reached through the University of Minnesota Libraries' link to free e-journals. A search conducted of issues 1975 through fall 2017 for the following yielded no results: cultural competence, cultural competency, cultural competencies, cross-cultural competency, cross-cultural competencies, cultural diversity competency, cultural diversity competencies, global mindedness, international mindedness, inter-cultural competency, inter-cultural competencies, intercultural competency, intercultural competencies. The phrase inter-cultural yielded two results not pertinent.

${ }^{46}$ I searched Archives \& Records dated 2013 through autumn 2016 only (due to an embargo of the last eighteen months) and its predecessor, Journal of the Society of Archivists, dated 1974 through 2012, via EBSCOhost Academic Search Premier database offered by the University of Minnesota Libraries. A search for terms cultural competence, cultural competency, cultural competencies, cross-cultural competency, cross-cultural competencies, cultural diversity competency, cultural diversity competencies, global mindedness, international mindedness, inter-cultural competency, inter-cultural competencies, intercultural competency, intercultural competencies, inter-cultural revealed no results.

${ }^{47}$ Rebecca Hankins and Miguel Juárez, "Art in Special Collections: Latino and African American Fine Art and Photography Collections in Academic Institutions," Art Documentation 29, no. 1 (2010): 33.

${ }^{48}$ Montiel-Overall, Nuñez, and Reyes-Escudero, Latinos in Libraries, Museums, and Archives, chapter 6, "Special Collections and Archives." 
${ }^{49}$ Montiel-Overall, Nuñez, and Reyes-Escudero, Latinos in Libraries, Museums, and Archives, xii.

${ }^{50}$ Montiel-Overall, Nuñez, and Reyes-Escudero, Latinos in Libraries, Museums, and Archives, xii.

${ }^{51}$ Mark Shelstad, "Getting to Tier 1 by Revitalizing a Special Collections Program with Cultural Competence," Journal of Contemporary Archival Studies 5, no. 1 (2018): 17.

${ }^{52}$ Kelvin L. White and Anne J. Gilliland, "Promoting Reflexivity and Inclusivity in Archival Education, Research, and Practice,” Library Quarterly 80, no. 3 (2010): 231.

${ }^{53}$ For more on this, see the chapter by Anne J. Gilliland and Sue McKemmish, "Archival and Recordkeeping Research: Past, Present and Future,” in Research Methods: Information, Systems, and Contexts, ed. Kirsty Williamson and Graeme Johanson (Oxford: Chandos Publishing, 2017); Anthony Dunbar, "Introducing Critical Race Theory to Archival Discourse: Getting the Conversation Started," Archival Science 6, no. 1 (2006): 109-29.

54 “Five Things to Read about Critical Librarianship," http://acrl.ala.org/IS/wp-content/uploads/20170602_ research_5Things.pdf; Laura L. Bierema, Implementing a Critical Approach to Organization Development (Malabar, Fla.: Krieger, 2010), 98; Chris Taylor, "From Systemic Exclusion to Systemic Inclusion: A Critical Look at Museums,” Journal of Museum Education 42, no. 2 (2017): 160.

${ }^{55}$ Michelle Caswell, Ricardo Punzalan, and T-Kay Sangwand, "Critical Archival Studies: An Introduction,” Journal of Critical Library and Information Studies 1, no. 2 (2017): 2.

${ }^{56}$ Ricardo L. Punzalan and Michelle Caswell, "Critical Directions for Archival Approaches to Social Justice,” Library Quarterly 86, no. 1 (2016): 29.

${ }^{57}$ Todd Honma, "Trippin' Over the Color Line: The Invisibility of Race in Library and Information Studies," InterActions: UCLA Journal of Education and Information Studies 1, no. 2 (2005).

${ }^{58}$ Kelvin L. White, "Race and Culture: An Ethnic Studies Approach to Archival and Recordkeeping Research in the United States," in Research in the Archival Multiverse, ed. Anne J. Gilliland, Sue McKemmish, and Andrew J. Lau (Clayton, Victoria: Monash University Publishing, 2017): 360.

${ }^{59}$ David James Hudson, “On 'Diversity' as Anti-Racism in Library and Information Studies: A Critique," Journal of Critical Library and Information Studies 1, no. 1 (2017): 16. See 14-18 for the wider discussion on individualism.

${ }^{60}$ J. J. Ghaddar, “The Spectre in the Archive: Truth, Reconciliation, and Indigenous Archival Memory," Archivaria 82 (2016): 7.

${ }^{61}$ Ghaddar, "The Spectre in the Archive," 16.

${ }^{62}$ Montiel-Overall, Nuñez, and Reyes-Escudero, Latinos in Libraries, Museums, and Archives, 22.

${ }^{63}$ James Elmborg and Scott Walter, "Critical Thinking About 'Getting Research Published' in College \& Research Libraries,” College \& Research Libraries 76, no. 1 (2015): 4. Authors state that In the Library with the Lead Pipe journal "pushes forward a critical dimension. . . ."

${ }^{64}$ Blackburn, "The Intersection between Cultural Competence and Whiteness," under "Whiteness in Libraries."

${ }^{65}$ Montiel-Overall, Nuñez, and Reyes-Escudero, Latinos in Libraries, Museums, and Archives, 189.

${ }^{66}$ Montiel-Overall, “Cultural Competence,” 190.

${ }^{67}$ Punzalan and Caswell, "Critical Directions," 32.

${ }^{68}$ On the longer history of EDI in the American archival profession and SAA, see for example these works and their sources cited: Elizabeth W. Adkins, "Our Journey toward Diversity-and a Call to (More) Action,” American Archivist 71, no. 1 (2008): 21-49; Mark A. Greene, "A Critique of Social Justice as an Archival Imperative: What Is It We're Doing That's All That Important?, American Archivist 76, no. 2 (2013): 302-34; Alex H. Poole, "The Strange Career of Jim Crow Archives: Race, Space, and History in the Mid-Twentieth-Century American South," American Archivist 77, no. 1 (2014): 23-63; Mario H. Ramirez, "Being Assumed Not to Be: A Critique of Whiteness as an Archival Imperative,” American Archivist 78, no. 2 (2015): 348-50 particularly.

${ }^{69}$ Additional Matter (Contributors, Ads, Council Minutes, etc.), American Archivist 73, no. 1 (2010): 316-18.

${ }^{70}$ Rebecca Hankins, phone conversation with author, August 17, 2017. The adjective "meaningful" in ". . . was not yet making meaningful progress on diversity and inclusion issues" is my addition to Hankins's general point on the diversity-related revelations that Protocol discussions brought to light. 
${ }^{71}$ Helen Wong Smith and Rebecca Hankins, "Cultural Diversity Competence \& Diversity in the Archives," webinar presentation for the San Jose State University SAA Student Chapter, October 18, 2016, www.youtube.com/watch?v=V5affH8VazA; see particularly 4:20-4:35.

72 Society of American Archivists, "Introduction and the Cultural Competency Continuum," Cultural Diversity Competency; Recommended Approach to Training \& Implementation for Archivists, webinar, from 1:26 through 1:37, accessed via members' online education portal on September 8, 2017.

${ }^{73}$ See for example, actions listed in Nancy Beaumont and Felicia Owens, Review of Strategic Plan Actions and Timelines, https://www2.archivists.org/sites/all/files/0717-1-III-B-StratPlanActions-Dashboard. pdf; Society of American Archivists, "SAA Council Refines Strategic Plan, Focuses on Diversity and Cultural Competency,” press release (November 13, 2014), https://www2.archivists.org/news/2014/ saa-council-refines-strategic-plan-focuses-on-diversity-and-cultural-competency; Tanya ZanishBelcher, "Some Remarks on the SAA Council's Recent Statement on White Supremacy," Off the Record (August 21, 2017); Nancy Beaumont, "From the Executive Director, " Archival Outlook (July/ August 2017): 20: “. . . and Education Director Kara Adams is working with Helen Wong Smith on a new online course on cultural competency that we'll provide free to SAA members." The online workshop with Wong Smith was available on the SAA website in 2017; an in-person workshop was offered at the 2018 Annual Meeting.

${ }^{74}$ I conducted a search for cultural competency in the SAA Annual Meeting preliminary programs dated 2003 through 2017, via keyword searches, close readings of electronic versions when available, and close readings of paper copies of those not available in electronic form. Preliminary programs provide meeting and workshop description narratives, along with full session titles and abstracts. I searched for cultural competency, cultural competencies, or intercultural and also read closely for any use of a word with competenc* as its root, which captured cultural diversity competency. Results are described in the article text. At the 2018 Annual Meeting, two session titles incorporated the phrase and clearly engaged in the topic; a preconference workshop on "Cultural Diversity Competency" was offered; and the program's "description” tag library for educational sessions includes "cultural competency" and "cultural competencies."

${ }^{75}$ Helen Wong Smith, 2017 SAA Research Forum Agenda, https://www2.archivists.org/sites/all/files/ Smith_ResearchForumAbstractBio2017.pdf; Ellen Engseth, Athena Jackson, Dominique Luster, and Abdi Roble, "Culture, Competencies, and Colleagues: a Café on divers*," Session 202, SAA Annual Meeting, July 27, 2017, Portland, Oregon. As organizer of session 202, I am aware that our intention was to include elements of the phrase in the title to clearly reference cultural competency.

${ }^{76}$ Samantha Winn, "Deconstructing Whiteness in Archives: Opportunities for Self-Reflection," Session 211, SAA Annual Meeting, August 4, 2016, Atlanta, Georgia.

77 Janet Ceja Alcala, Hannivett Nabahe, Jessica Kniest, Monique Perez, "Pedagogical Strategies for Fostering Pluralism in Archives Studies," poster presentation, SAA Annual Meeting, August 2015, Cleveland, Ohio.

${ }^{78}$ Helen Wong Smith, "Remarks to the Leadership Plenary," SAA Annual Meeting, August 2015, Cleveland, Ohio.

${ }^{79}$ The mid-twentieth-century movement to broaden historical sources is much discussed in archival literature. For example, on oral history, see Ellen Swain, "Oral History in the Archives: Its Documentary Role in the Twenty-First Century,” American Archivist 66, no. 1 (2003): 139-58; Jessica Wagner Webster, “'Filling the Gaps': Oral Histories and Underdocumented Populations in The American Archivist, 1938-2011,” American Archivist 79, no. 2 (2016): 254-82. The 2011 SAA Core Values of Archivists states: "Archivists collectively seek to document and preserve the record of the broadest possible range of individuals, socio-economic groups, governance, and corporate entities in society. Archivists embrace the importance of identifying, preserving, and working with communities to actively document those whose voices have been overlooked or marginalized. They seek to build connections to under-documented communities to support: acquisition and preservation of sources relating to these communities' activities, encouragement of community members' use of archival research sources, and/or formation of community-based archives. Archivists accept and encourage a diversity of viewpoints on social, political, and intellectual issues, as represented both in archival records and among members of the profession. . ," https://www2.archivists.org/ statements/saa-core-values-statement-and-code-of-ethics.

${ }^{80}$ On restorative or iterative description, see, for example, Kelly Bolding, "De-Centering Whiteness in the Archives," Session 503, presentation slides, Midwest Archives Conference, March 25, 
2018, Chicago, Illinois, https://docs.google.com/presentation/d/1MhOXx5ZlVjb_8pfvvFquMqLsUU1 OHFFMT4js5EP4qnA/mobilepresent?slide=id.p; and Erin Baucom, "An Exploration into Archival Descriptions of LGBTQ Materials,” American Archivist 81, no. 2 (2018): 65-83.

${ }^{81}$ Dominique Luster, "\{Cultural Competency \& Conscious Language in Archival Descriptive Practices\}," Society of American Archivists Annual Meeting, July 27, 2017, Portland, Oregon.

${ }^{82}$ Teenie Harris Archive, "About the Archive," http://teenie.cmoa.org/ArchiveStories.aspx.

${ }^{83}$ Luster, "\{Cultural Competency \& Conscious Language in Archival Descriptive Practices\}."

${ }^{84}$ For more on Roble's work, see recording of Session 202, "Culture, Competencies, and Colleagues: a Café on divers*," Society of American Archivists Annual Meeting, July 27, 2017, Portland, Oregon.

${ }^{85}$ The information provider in this case was Roble and other Somali Americans, and the location was a community center and mosque. Press and Diggs-Hobson, "Providing Health Information to Community Members Where They Are," 408.

${ }^{86}$ With thanks to Andrew Palahniuk, instructional designer, University of Minnesota Libraries, for the design work and consultation.

87 "Dominant majority" holds various meanings that are contextual and nuanced. I am referring particularly to racial and ethnic identity: according to the 2004 census of American archivists, for example, "only $7.0 \%$ of all $\mathrm{A}^{*}$ CENSUS respondents reported belonging to one or more ethnic or racial groups other than Caucasian. ... Victoria Irons Walch, Nancy Beaumont, Elizabeth Yakel, Jeannette Bastian, Nancy Zimmelman, Susan Davis, and Anne Diffendal, "A*CENSUS (Archival Census and Education Needs Survey in the United States)," American Archivist 69, no. 2 (2006): 332. Other dominant identities in the U.S. archives profession may include class identity, education credentials, gender and sexuality identity, and so on.

${ }^{88}$ Randall C. Jimerson, Archives Power: Memory, Accountability, and Social Justice (Chicago: Society of American Archivists, 2009), 340.

${ }^{89}$ Chris Taylor articulates next practice evolving out of best practice; see Taylor, "Getting Our House in Order," 26.

\section{ABOUT THE AUTHOR}

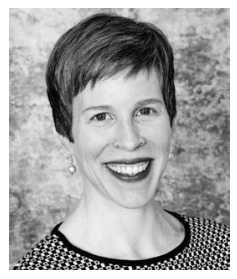

Ellen Engseth is curator of the Immigration History Research Center Archives and head of Migration and Social Services Collections in the Department of Archives \& Special Collections, University of Minnesota Libraries. Previously, she held positions at the University of Wisconsin-Milwaukee, the University of Illinois at Urbana-Champaign, and North Park University. She earned a master of library and information science and a master of arts in history from the University of Wisconsin-Milwaukee. She teaches a study abroad course occasionally with the iSchool at the University of Wisconsin-Milwaukee. Her areas of practice and research include access and an inclusive historical record, user engagement, international experiences, and professional development. 